\title{
Determinants of Exclusive Breastfeeding Practices of Female Healthcare Workers in Jakarta, Indonesia
}

\author{
Siti Rapingah ${ }^{1}$, Nova Muhani2 ${ }^{* *}$, Besral ${ }^{3}$, Poppy Yuniar ${ }^{4}$
}

\begin{abstract}
1Department of Nursing, Faculty of Health Science, Universitas Islam Assyafiyah, Jakarta, Indonesia
2Department of Biostatistics and Epidemiology, Faculty of Public Health, Universitas Malahayati, Bandar Lampung, Indonesia

${ }^{3}$ Department of Biostatistics and Population Faculty of Public Health, Universitas Indonesia, Depok, Indonesia

${ }^{4}$ School of Public Health, Curtin University, Perth, Australia
\end{abstract}

\begin{abstract}
The World Health Organization in 2019 recommended that mothers worldwide exclusively breastfeed their infants for the child's first six months to achieve optimal growth, development, and health. Indonesia had not fulfilled the global standard of breastfeeding rate, so that there was low coverage of exclusive breastfeeding in East Jakarta, especially for female health care workers. This study aimed to determine the factors associated with exclusive breastfeeding practices of health care workers. This study was a quantitative study using a cross-sectional design. The recruited sample consisted of 85 female primary healthcare workers with infants aged 6-24 months. Data were collected using self-administered questionnaires. Logistic regression analysis was applied to identify factors associated with exclusive breastfeeding. The results showed that the proportion of exclusive breastfeeding was $54.1 \%$. Variables associated with exclusive breastfeeding were knowledge, attitude, family support, co-worker support, and healthcare worker support. Multivariate analysis showed that knowledge and age were the dominant factors of exclusive breastfeeding practices with an odds ratio (OR) adjusted OR of 14 and 5, respectively. Knowledge was an influential factor in the success of exclusive breastfeeding. Therefore, creating a training program related to breastfeeding would be expected to improve knowledge. Besides, a supportive policy such as providing breastfeeding facilities was needed.
\end{abstract}

Keywords: exclusive breastfeeding, female healthcare worker, knowledge, support

\section{Introduction}

The health status of a country can be determined from the maternal mortality rate (MMR) and infant mortality rate (IMR). The main causes of infant mortality are respiratory infection and diarrhea. According to World Health Organization (WHO) data, $53 \%$ of acute pneumonia and $55 \%$ of infant deaths are due to diarrhea caused by poor nutrition during the first six months of life (not exclusive breastfeeding/suboptimal breastfeeding). ${ }^{1}$

One of the efforts to reduce IMR is through the promotion of exclusive breastfeeding. ${ }^{2}$ Indonesia has committed to implement such a program. Various policies have been ratified to support exclusive breastfeeding programs, including Law No. 33 of 2012 concerning Exclusive Breastfeeding, Government Regulation Number 3 of 2010 concerning the Application of Ten Steps to Breastfeeding Success, and Government Regulation No. 15 of 2014 concerning Administrative Sanctions for Healthcare Personnel Inhibiting the Success of Exclusive Breastfeeding. ${ }^{3}$ Basic Health

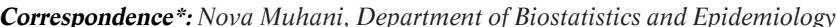
Faculty of Public Health, Malahayati University, Rektorat Building 5th Floor, Pramuka Street No. 27 Kemiling, Bandar Lampung 35153, Indonesia, E-mail: muhaninova@gmail.com, Phone: +62-721-273592
Research in 2018 showed that the exclusive breastfeeding rate in Indonesia up to six months was only $41 \% .^{4}$ This figure is still far from the national coverage target of $75 \%$. Based on data from the 2012 World Breastfeeding Trend Initiative on breastfeeding conditions, Indonesia ranked 49th of 51 countries with a breastfeeding rate of only $27.5 \% .^{5}$

Working mothers is one of the causes of exclusive breastfeeding failure.6,7 Basic Health Research in 2013 showed that $89.6 \%$ of working mothers in Indonesia gave prelacteal feeds to their babies. ${ }^{8}$ Low coverage of exclusive breastfeeding in East Jakarta (28\%) was found especially among healthcare workers (50\%). ${ }^{9}$ A study conducted in Ethiopia among 178 healthcare workers (doctors, nurses, and midwives) showed that only $35.9 \%$ of respondents practiced exclusive breastfeeding, ${ }^{10}$ while equivalent study in Nigeria among 626 doctors showed that only $11 \%$ practiced exclusive breastfeeding. ${ }^{11}$

World Health Organization (WHO) recommends mothers worldwide to exclusively breastfeed infants for the child's first six months to achieve optimal growth, 
development, and health. ${ }^{12}$ Thereafter, they should be given nutritious complementary foods and continue breastfeeding up to the age of two years or beyond. Factors inhibiting breastfeeding success are categorized as internal and external. Internal factors include a lack of knowledge about lactation management, the benefits of breastfeeding, and the negative impact of not breastfeeding. External factors are related to everything that does not need to happen if the internal factors are met. ${ }^{13}$ This correlates with the low coverage of breastfeeding in East Jakarta, which impacts on underweight children, which is $13.8 \%$ and malnutrition is $2.92 \% .9$

Preliminary studies conducted by Mehkari S, et al.,14 showed that among four healthcare workers in KarachiPakistan, only one was practicing exclusive breastfeeding. Several inhibiting factors were lack of knowledge of lactation management, mothers' nipple and breast pain, low breast milk supply, attitude towards breastfeeding, and confidence. The success of healthcare workers in providing exclusive breastfeeding is very important because it plays an important role in promoting and supporting the implementation of exclusive breastfeeding. One of the success factors is influenced by knowledge, and personal experience referred to as learning by experience. ${ }^{14}$ The low coverage of breastfeeding among healthcare workers in particular correlates with underweight (below the red line). The incidence of severe malnutrition in Jakarta, according to authors, is very important to study because healthcare workers play a key role in the promotion and support for exclusive breastfeeding. The study aims to determine the factors related to exclusive breastfeeding behavior among healthcare workers at the primary health care throughout East Jakarta.

\section{Method}

This observational study was conducted using the correlational method. The study design was cross-sectional and the data collection technique was total sampling. The study population included all female health workers who had babies ages 6-24 months. The sample of 85 female healthcare workers was drawn from the total population. The inclusion criteria were not taking pregnancy leave and agreeing to participate in this study (by providing written informed consent). The exclusion criteria were healthcare workers who had delivered severely ill or stillborn babies, had twins, or were on leave, study. The respondents comprised female physicians, dentists, nurses, midwives, nutritionists, pharmacists, public health experts/environmental health experts, and laboratory analysts.

Data collection occurred from April to May 2015 in 10 primary health care in East Jakarta. Data collection used a structured questionnaire consisting of the determinant variable of exclusive breastfeeding (predisposing, enabling, and reinforcing factors). Predisposing factors consist of several variables. Age at-risk categories were 20-35 years, risk-free categories were 20 to 35 years, parity in good multipara categories (women who have given birth more than once), poor categories of primipara (women who have given birth once), types of labor were vaginal delivery and cesarean section, supportive knowledge was "good", the supportive attitude was positive. Enabling factors consisted of the availability of good facilities and had followed lactation management. Reinforcing factors were the support of family, superiors, friends, and health workers.

The data collected was then inputted and cleaned, so that they could be analyzed. These variables were univariate, bivariate, and multivariate. Univariate analysis was done for each variable with the proportional results of each. Bivariate analysis with chi-square with the results whether there was a relationship between each independent variable and the dependent variable if the $\mathrm{p}$ value was less than 0.05 was considered to statistical significance. Multiple logistic regressions with backward determinant modeling found significant determinant factors. All independent variables had the same position since no independent variables were considered as the main variable. The principle of modeling was to produce a significant, valid, and parsimonious model. There are five steps in backward stepwise regression. Step one was identifying potential covariates; step two was analyzing each covariate on the dependent variable where $p$-value $<0.25$ entered into the logistic regression model; step three was getting the model to eliminate the independent variable starting from the variable with the highest p-value, the confounder was considered if there was a change of $10 \%$ or more odds ratio (OR); step four the confounding remained in the model. The final step was finding the significant determinant factor.

\section{Results}

Table 1 showed that the proportion of respondents who provided exclusive breastfeeding was $54.1 \%$. Predisposing factors related to exclusive breastfeeding were knowledge and attitude. The enabling factor was the availability of facilities. The reinforcing factor was family supports, colleague supports, and health worker supports.

The knowledge questions on Table 2 showed that almost all respondents knew of exclusive breastfeeding. Only two questions receive incorrect answers, namely "Reducing the risk of osteoporosis" (25.9\%) and "How long can breast milk sit out at room temperature?" $(47.1 \%)$.

The logistic regression results (Table 3 ) showed that the determinants for providing exclusive breastfeeding were maternal knowledge and age. The dominant factors 
Table 1. Predisposing, Enabling, and Reinforcing Factors for Exclusive Breastfeeding among Female Healthcare Workers

\begin{tabular}{|c|c|c|c|c|c|c|}
\hline Variable & Category & $\begin{array}{c}\text { Total } \\
(\mathbf{N}=\mathbf{8 5})\end{array}$ & $\begin{array}{l}\text { Non-Exclusive } \\
\text { Breastfeeding } \\
(\mathrm{N}=39)\end{array}$ & $\begin{array}{c}\text { Exclusive } \\
\text { Breastfeeding } \\
(\mathrm{N}=46)\end{array}$ & p-value & $\begin{array}{c}\text { OR } \\
(95 \% \mathbf{C I})\end{array}$ \\
\hline \multicolumn{7}{|l|}{ Predisposing } \\
\hline \multirow[t]{2}{*}{ Age (year) } & $<20$ or $>35$ & 22 & 59.1 & 40.9 & 0.232 & $2.1(0.7-5.5)$ \\
\hline & $20-35$ & 63 & 41.3 & 58.7 & & \\
\hline \multirow[t]{2}{*}{ Parity good } & Primipara & 48 & 50.0 & 50.0 & 0.517 & $1.5(0.6-3.4)$ \\
\hline & Multipara & 37 & 40.5 & 59.5 & & \\
\hline \multirow[t]{2}{*}{ Types of labor } & Cesarean section & 51 & 49.0 & 51.0 & 0.625 & $1.4(0.5-3.2)$ \\
\hline & Vaginal delivery & 34 & 41.2 & 58.8 & & \\
\hline \multirow[t]{2}{*}{ Knowledge } & Good enough & 37 & 78.4 & 21.6 & $0.001 *$ & $13.8(4.8-39.3)$ \\
\hline & Good & 48 & 20.8 & 79.2 & & \\
\hline \multirow[t]{2}{*}{ Attitude } & Negative & 39 & 59.0 & 41.0 & $0.044^{*}$ & $2.7(1.1-6.5)$ \\
\hline & Positive & 46 & 34.8 & 65.2 & & \\
\hline \multicolumn{7}{|l|}{ Enabling } \\
\hline \multirow[t]{2}{*}{ Availability of facilities } & No & 11 & 73.1 & 26.9 & $0.002^{*}$ & $5.3(1.9-14.7)$ \\
\hline & Yes & 74 & 33.9 & 66.1 & & \\
\hline \multirow[t]{2}{*}{ Lactation management training } & Never & 51 & 46.8 & 53.2 & 0.899 & $1.5(0.3-6.5)$ \\
\hline & Ever & 34 & 37.5 & 62.5 & & \\
\hline \multicolumn{7}{|l|}{ Reinforcing } \\
\hline \multirow[t]{2}{*}{ Family supports } & No & 23 & 78.3 & 21.7 & $0.001 *$ & $7.0(2.3-21.6)$ \\
\hline & Yes & 62 & 33.9 & 66.1 & & \\
\hline \multirow[t]{2}{*}{ Supervisor supports } & No & 20 & 65.0 & 35.0 & 0.088 & $2.8(0.9-7.9)$ \\
\hline & Yes & 65 & 40.0 & 60.0 & & \\
\hline \multirow[t]{2}{*}{ Colleague supports } & No & 34 & 61.8 & 38.2 & $0.029 *$ & $2.9(1.2-7.3)$ \\
\hline & Yes & 51 & 35.3 & 64.7 & & \\
\hline \multirow[t]{2}{*}{ Health worker supports } & No & 29 & 65.5 & 34.5 & $0.017 *$ & $3.4(1.3-8.7)$ \\
\hline & Yes & 56 & 35.7 & 64.3 & & \\
\hline
\end{tabular}

Notes: OR: Odd Ratio; CI: Confidence Interval; *Variables that were significantly related, p-value $<0.05$

Table 2. Distribution of Respondents According to Mothers' Knowledge of Correct Answers about Exclusive Breastfeeding

\begin{tabular}{lcc}
\hline & \multicolumn{2}{c}{ Correct } \\
\cline { 2 - 3 } Knowledge & N & $\%$ \\
\hline Definition of exclusive breastfeeding & 84 & 98.8 \\
Actions are taken when breast milk has not come out & 84 & 98.8 \\
Factors affecting breast milk production & 79 & 92.9 \\
$\quad$ - Mother's psychological condition & 80 & 94.1 \\
$\quad$ - Mother's diet & 66 & 77.6 \\
$\quad$ Family/husband support & & 84.7 \\
Benefits of breastfeeding for mother & 72 & 25.9 \\
$\quad$ Reducing the risk of breast cancer & 22 & 95.3 \\
$\quad$ - Beducing the risk of osteoporosis & 81 & 91.8 \\
$\quad$ - Saving on household expenses & 78 & 47.1 \\
How long breast milk can sit out at room temperature & 40 & 72.9 \\
When lactation management be started & 62 & 80.0 \\
The cause of failure to do exclusive breastfeeding & 68 & 56.5 \\
Risks of feeding baby solid food too soon & & 92.9 \\
$\quad$ - Indigestion & 48 & 87.1 \\
$\quad$ Increasing the chance the baby will get sick & 79 & 54.1 \\
\hline Risks of introducing solids too late & & 74 \\
$\quad$ Babies may do not get the nutrients they need & 46 & \\
\hline
\end{tabular}

related to the exclusive breastfeeding practices were also knowledge and age. Female healthcare workers with good knowledge had a 15 times greater likelihood of providing exclusive breastfeeding than those with less knowledge. After controlling for the availability of facilities, family support, colleague support, and healthcare workers supports variables, mothers aged 20-35 years had five times more likelihood of providing exclusive breastfeeding than those aged $<20$ years or $>35$ years.

Based on the results of thequantitative study, it was found that $40.9 \%$ of respondents provided exclusive breastfeeding and $59.1 \%$ did not. These results only il- 


$\begin{aligned} & \text { Table 3. Multivariate Analysis of Exclusive Breastfeeding Practices among Female } \\
& \text { Healthcare Workers }\end{aligned}$
\begin{tabular}{lcccc} 
Variable & $\beta$ & p-value & $\begin{array}{c}\text { Adjusted } \\
\text { Odds Ratio }\end{array}$ & $\begin{array}{c}\text { Confident } \\
\text { Interval (95\%) }\end{array}$ \\
& & & 4.9 & $1.1-21.9$ \\
Age 20-35 years & 1.601 & 0.035 & 14.8 & $4.0-54.4$ \\
Good knowledge & 2.699 & 0.000 & 2.7 & $0.6-12.1$ \\
Have available facilities & 1.015 & 0.177 & 2.7 & $0.5-14.9$ \\
Have family support & 1.026 & 0.230 & 1.4 & $0.4-5.8$ \\
Have colleague support & 0.373 & 0.600 & 1.7 & $0.4-6.8$ \\
Have health worker support & 0.541 & 0.443 & & \\
\hline
\end{tabular}

lustrated the percentage of exclusive breastfeeding for healthcare workers and more excavations were carried out for reasons that give exclusive breastfeeding.

The result revealed that respondents who did not breastfeed because of abrasions while breastfeeding had a little of breast milk, such that they felt that it was not enough for the baby. Respondents who managed to give exclusive breast milk said that it was very important for babies. Most of all, it represented a strong commitment to continue to provide exclusive breastfeeding, so it could be concluded that the success of breastfeeding for women healthcare workers influenced not only the knowledge factor but also the presence of a strong commitment factor.

\section{Discussion}

This study showed that the exclusive breastfeeding rate among female healthcare workers in primary health care throughout East Jakarta in April-May 2015 was $54.1 \%$. This result was higher than the rates based on the Basic Health Research in 2013 (30.2\%), ${ }^{8}$ and the exclusive breastfeeding coverage throughout East Jakarta $(28.0 \%) .{ }^{9}$ However, these rates should be higher because the respondents were healthcare workers who should have better knowledge than people who were not in the health care profession. This difficulty of nurses and midwives to successfully practice exclusive breastfeeding may impair their ability and effectiveness in promoting breastfeeding. ${ }^{14}$

The present study continued to find out the reason(s) health care workers did not give exclusive breastfeeding. A previous study by Akodu, et al., ${ }^{15}$ demonstrated that $35 \%$ of mothers stopped breastfeeding several weeks postpartum because they felt their breast milk was deficient and the baby was dissatisfied. So the type of fluid given to the babies before breast milk secreted were formula milk $(11.7 \%)$ and dextrose $(1.2 \%)$. Authors have similarly mentioned in the study that bottle feeding was practiced by $77.4 \%$ of health professionals; however, only $21.9 \%, 16$ was due to bottle feeding-related hazards. Diarrhea, vomiting, and acute respiratory infection (ARI) were the commonly identified illnesses found among the children on bottle feed, as concluded from their results that bottle feeding was mostly practiced by educated mothers, where healthcare providers, despite their education and awareness, were practicing bottle feeding. Respiratory infections were identified as the important risks associated with bottle feeding, and that it was the leading cause of malnourishment among children.

To support the success of breastfeeding in working women, the Ministry of Manpower's regulation, Article 83 of Law No. 13 of 2003, those female employees who are still breastfeeding are allowed to breastfeed or at least pump breast milk during working hours. ${ }^{17}$ Companies are also encouraged to have a proper nursing room. Besides, the Regulation of the Minister of Health of the Republic of Indonesia Number 15 of 2013 concerning Procedures for Providing Special Facilities for Breastfeeding and/or Pumping Breast milk. ${ }^{3}$

World Health Organization program entitled Ten Steps to Successful Breastfeeding, ${ }^{17}: 1$. Contains an infant feeding policy that is routinely communicated to staff and parents. Establishes ongoing monitoring and data-management systems; 2 . Ensures that staff have sufficient knowledge, competence, and skills to support breastfeeding; 3 . Discusses the importance and management of breastfeeding with pregnant women and their families; 4. Facilitates immediate and uninterrupted skinto-skin contact and encourages mothers to initiate breastfeeding as soon as possible after birth; 5 . Supports mothers to initiate and maintain breastfeeding and manage common difficulties; 6 . Encourages mothers not to provide breastfed newborns any food or fluids other than breast milk, unless medically indicated; 7. Enables mothers and their infants to remain together and practice rooming-in 24 hours a day; 8 . Encourages mothers to recognize and respond to their infants' cues for feeding; 9. Counsels mothers on the use and risks of feeding bottles, teats, and pacifiers; and 10. Coordinates discharge so that parents and their infants have timely access to ongoing support and care. This program is relevan with study by Shandi, et al., ${ }^{18}$ demonstrated that mothers with a practicing skin-to-skin contact with early initiation and (rooming-in) were more likely to exclusively breastfeed 
$(\mathrm{OR}=2.36)$

Other findings included bivariate analysis indicated that a mother's age is not significantly associated with exclusive breastfeeding practices. This finding was confirmed in a previous study, ${ }^{16}$ while other result showed different findings that age was significantly associated with exclusive breastfeeding. ${ }^{19}$ Delivery by cesarean section inhibited breastfeeding. Another study showed that mothers who had had cesarean delivery tended to delay breastfeeding compared to mothers experiencing vaginal delivery. ${ }^{20}$ Parity was not significantly associated with exclusive breastfeeding practices. This finding was confirmed in a previous study, ${ }^{21}$ while several studies stated that parity was significantly associated with exclusive breastfeeding practices. ${ }^{22,23}$ Exclusive breastfeeding associated significantly with a place of delivery and maternal education. ${ }^{20}$

Lactation management training aimed to increase knowledge and to solve problems found while breastfeeding, especially for healthcare workers. This training was valuable because respondents in this study were healthcare workers expected to have better knowledge than the general public. After all, health workers had an important role that should promote, support the implementation of exclusive breastfeeding. ${ }^{14,26}$ Lactation management including breastfeeding technique, breastfeeding technology, breastfeeding problem solving, and infant issues. ${ }^{26}$ Bivariate analysis showed that lactation management training was not significantly related to exclusive breastfeeding behavior. Based on the quantitative results, only eight respondents $(9.4 \%)$ attended training related to breastfeeding.

The availability of policy, breastfeeding guidelines, and training for most staff on exclusive breastfeeding contributed to higher exclusive breastfeeding knowledge and counseling skills among health workers. ${ }^{24,26}$ This, in turn, might have led to women seeking support for breastfeeding issues immediately after delivery. During these times, healthcare workers also reinforced the idea of exclusive breastfeeding and its importance. This result differed from a previous study. ${ }^{25}$

Mothers needed support to achieve breastfeeding success. ${ }^{22}$ Family support would influence the mother's decision to provide exclusive breastfeeding. Family support was significantly related to exclusive breastfeeding practices related to a study in Yogyakarta. Family support was significantly associated with a higher likelihood of mothers practicing exclusive breastfeeding. ${ }^{23}$ This result was in line with the previous study that stated that the husband plays an important role in supporting breastfeeding success and increasing breastfeeding rates. ${ }^{27}$ Mothers required paternal support because fathers could also help in sourcing information on breastfeeding, provide encouragement and motivation, and involve in deci- sion-making, practical support, and emotional support for breastfeeding. A husband's attitude toward breastfeeding, whether positive or negative, could influence the mother's breastfeeding practices. ${ }^{27}$

Failure of exclusive breastfeeding for female healthcare workers often occured after three months of leave and starting to work. Many experienced a decrease in breast milk production because mothers felt tired at work, causing husbands and families to worry about insufficient breast milk. Finally, the family provided formula milk to the baby.

The multivariate analysis showed that the mother's knowledge and attitude were significantly associated with exclusive breastfeeding behavior. Mothers having good knowledge were 14.8 times more likely to provide exclusive breastfeeding than mothers with good-enough knowledge. This result was similar to study findings from Ethiopia, ${ }^{28}$ Nepal, ${ }^{29}$ and Tanzania, ${ }^{25}$.This impact could be partly explained by mothers' improved knowledge of the benefits of breastfeeding for themselves and their infants, as well as the risks of not breastfeeding, thus improving the likelihood that mothers will breastfeed. Previous studies showed that mothers with good knowledge had 2.6 and 2.7 times the likelihood of providing exclusive breastfeeding than good enough knowledge and negative attitudes, respectively. ${ }^{28}$

Various studies have been conducted in the past covering this topic, but the present study's setting was mothers from healthcare backgrounds who were assessed about their breastfeedings. There were some limitations in this study, especially the sample size, as it was difficult for us to find mothers who fulfilled our inclusion criteria. Others had children of more than ten years of age, which may have caused recall bias. It was also difficult to ask study participants to fill in the forms as they were not interested in sharing their personal experiences. Data were collected through self-administered questionnaires, so there was a chance of subjective bias. Future study avenues to look into this topic were from the study's point of view and highlighted the problem faced by healthcare providers for practicing appropriate breastfeeding and weaning practices.

\section{Conclusion}

The description of healthcare workers in East Jakarta who provided exclusive breastfeeding was relatively low (under 50\%). Several factors influenced exclusive breastfeeding practices in healthcare workers, including knowledge, attitudes, availability of facilities, family support, support from co-workers, and support from other healthcare workers. Based on the above factors, the most influential factor was mother knowledge.

There was low coverage of exclusive breastfeeding for healthcare workers in East Jakarta, even though authors 
know that healthcare workers are role models for the community. If healthcare workers have high success in exclusive breastfeeding and good knowledge, they would likely be more supportive of mothers providing exclusive breastfeeding to their babies. An inhibiting factor is family support, especially husbands and colleagues support. Health inhibiting factors in exclusive breastfeeding is lack of the mothers' commitment, lack of knowledge among family members, and problems in breastfeeding, including limited hours of rest. By contrast, a supporting factor in exclusive breastfeeding was colleagues' support.

Lactation management training makes it possible to improve health knowledge about lactation. This training is very important because good knowledge will greatly influence the success of exclusive breastfeeding. Practicing for themselves and having good knowledge will provide high self-confidence to promote exclusive breastfeeding. Providing ideas for healthcare workers who are still breastfeeding, allowing them to be more flexible in doing tasks, should be considered. Writing policies related to supervisor and colleague support for mothers to provide exclusive breastfeeding should be considered. Enacting "Lactation Breaks" that provide time for breastfeeding or expressing milk 30-60 minutes per day should be considered. Optimizing "exclusive breastfeeding corners" and using them as places to share experiences between healthcare workers who breastfeed and offering rewards to female healthcare workers who successfully provide exclusive breastfeeding should be considered.

\section{Abbreviations}

MMR: Maternal Mortality Rate; IMR: Infant Mortality Rate; WHO: World Health Organization; WBTI: World Breastfeeding Trend Initiative; OR: Odd Ratio; CI: Confidence Interval; ARI: Acute Respiratory Infection.

\section{Ethics Approval and Consent to Participate}

Informed consent was obtained individually from all respondents. The study was approved by the Health Service Office with a letter-number: 972-1-1.777-11.

\section{Competing Interest}

The author declares that there are no significant competing financial, professional, or personal interests that might have affected the performance or presentation of the work described in this manuscript.

\section{Availability of Data and Materials}

The authors confirm that the data supporting the finding of this study available within the article and its supplementary materials.

\section{Authors' Contribution}

SR conceived the idea, sampling design, and data collection, and analyzed and interpreted the study results. NM performed data collection, critically analyzed and interpreted the study results, drafted the manuscript, and submitted it. B gave his expert opinion in sampling design and critically analyzed the data for important intellectual content. PY gave her input in the manuscript drafting.

\section{Acknowledgment}

Acknowledgment of the contributions of editing proofreading in translation and copy editing of the manuscript to Editage Author Services. We would like to thank East Jakarta Sub Department for Health, for facilitating the study and the respondent women health workers at the primary health care in East Jakarta.

\section{References}

1. Gupta A, Dadhich JP, Suri S. How can global rates of exclusive breastfeeding for the first 6 months be enhanced?. Infant, Child, \& Adolescent Nutrition. 2013 [cited 2015 Apr 3]; 5 (3): 133-40.

2. World Health Organization. Infant and young child feeding. Geneva: World Health Organization; 2011. p. 155.

3. Kementerian Kesehatan Republik Indonesia. Peraturan Menteri Kesehatan Republik Indonesia Nomor 15 Tahun 2014 tentang Tata Cara Pengenaan Sanksi Administratif bagi Tenaga Kesehatan, Penyelenggara Fasilitas Pelayanan Kesehatan, Penyelenggara Satuan Pendidikan Kesehatan, Pengurus Organisasi Profesi di Bidang Kesehatan; 2014 [cited 2015 Mar 30].

4. Badan Penelitian dan Pengembangan Kesehatan Republik Indonesia. Riset kesehatan dasar (Basic Health Research) 2018; 2018. p. 1-220.

5. The International Baby Food Action Network-Breastfeeding Promotion Network of India. The world breastfeeding trends initiative: the state of breastfeeding 51 countries. Sweden: IBFAN; 2012 [cited 2015 Apr 20].

6. Kurniawan B. Determinan keberhasilan pemberian air susu ibu eksklusif. Jurnal Kedokteran Brawijaya. 2013; 27 (4): 236-40.

7. Zakiyah. Faktor-faktor yang berhubungan dengan pemberian ASI eksklusif di Kelurahan Semanan Kecamatan Kalideres Jakarta Barat tahun 2012 [Essay]. Universitas Indonesia; 2012 [cited 2019 Jul 2]. p. 64.

8. Badan Penelitian dan Pengembangan Kesehatan. Riset kesehatan dasar (basic health research) 2013. 2013. p. 1-384.

9. Dinas Kesehatan Jakarta. Profil kesehatan DKI Jakarta tahun 2017. 2018 [cited 2019 Oct 17]. p. 100.

10. Dachew BA, Bifftu BB. Breastfeeding practice and associated factors among female nurses and midwives at North Gondar Zone, Northwest Ethiopia: a cross-sectional institution based study. International Breastfeeding Journal. 2014 [cited 2015 Jan 20]; 9: 1-7.

11. Sadoh AE, Sadoh WE, Oniyelu P. Breastfeeding practice among medical women in Nigeria. Nigerian Medical Journal. 2011 [cited 2018 Jun 23]; 52: 7-12.

12. World Health Organizatiom. Continued breasfeeding for healthy growth and development of children; 2019.

13. World Health Organization. Global nutrition targets 2025 breastfeeding policy brief; 2012 [cited 2017 Aug 27].

14. Mehkari S, Zehra N, Yasin H, Rauf A, Jaliwala HA, Zehra T, et al. Breastfeeding and weaning: awareness and practices among female health providers working in a tertiary care hospital of Karachi-Pakistan. International Journal of Women's Health and Reproduction Sciences. 2014 [cited 2018 May 21]; 2: 281-6. 
15. Akudo, SO, Njokanma OF, Disu EA. The practice and determinant of prelacteal feeding among mother patronizing a private hospital. Annals of Health Research. 2015 [cited 2020 Jan 20]; 1 (1): 30-4.

16. Fikawati S, Syafiq. A. Gizi ibu dan bayi. 1st ed. Jakarta: Rajawali; 2015 [cited 2018 May 21].

17. World Health Organization. The ten steps to successful; 2019 [cited 2019 Jun 23]. p. 1.

18. Ayyu Sandhi, Gabrielle T. Lee, Roselyn Chipojola, Mega Hasanul Huda, Shu-Yu Kuo. The relationship between perceived milk supply and exclusive breastfeeding during the first six months postpartum: a crosssectional. International Breastfeeding Journal. 2020 [cited 31 Jan 21]; 15 (65): 2-11.

19. Teka B, Assefa H, Haileslassie K. Prevalence and determinant factors of exclusive breastfeeding practices among mothers in Enderta Woreda, Tigray, North Ethiopia: a cross-sectional study. International Breastfeeding Journal. 2015 [cited 2019 Jan 23]; 10: 1-7.

20. Husayni F. Prevalence of and risk factors for delayed onset of lactation in Saudi breastfeeding women. International Journal of Advanced Research. 2018 [cited 2020 Jul 20]; 6: 1062-71.

21. Kitano N, Nomura K, Kido M, Murakami K, Ohkubo T, Ueno M, et al. Combined effects of maternal age and parity on successful initiation of exclusive breastfeeding. Preventive Medicine Reports. 2016 [cited 2020 Aug 8]; 3: 121-6.

22. Tan KL. Factors associated with exclusive breastfeeding among infants under six months of age in peninsular Malaysia. International Breastfeeding Journal. 2011 [cited 2020 Jan 23]; 6 (1): 2.
23. Ratnasari D, Paramashanti BA, Hadi H, Yugistyowati A, Astiti D, Nurhayati E. Family support and exclusive breastfeeding among Yogyakarta mothers in employment. Asia Pacific Journal of Clinical Nutrition. 2017 [cited 2020 Feb 2]; 26 (May): S31-5.

24. Radzyminski S, Clark L. Health professionals' attitudes and beliefs about breastfeeding. Journal Perinatal Education. 2015; 24 (2): 102-9.

25. Nkala TE, Msuya SE. Prevalence and predictors of exclusive breastfeeding among women in Kigoma region, Western Tanzania: a community based cross-sectional study. International Breastfeeding Journal. 2011 [cited 2019 Sep 2]; 6 (1):17.

26. Patricia, Carvalho, Maria Olievera, Sandra Costa. Impact of health professional training in breastfeeding on their knowledge, skills, and hospital practices: a systematic review. Jurnal de Fedriatica. 2016 [cited 2021 Jan 21]; 92 (5): 436-45.

27. Brown A, Davies R. Fathers' experiences of supporting breastfeeding: challenges for breastfeeding promotion and education. Maternal \& Child Nutrition. 2014 [cited 2019 Aug 5]; 10 (4): 510-26.

28. Mekuria G, Edris M. Exclusive breastfeeding and associated factors among mothers in Debre Markos, Northwest Ethiopia: a cross-sectional study. International Breastfeeding Journal. 2015 [cited 2018 Oct 10]; 10 (1): 1.

29. Ulak M, Chandyo RK, Mellander L, Shrestha PS, Strand TA. Infant feeding practices in Bhaktapur, Nepal: a cross-sectional, health facility based survey. International Breastfeeding Journal. 2012 [cited 2019 Mar 20]; 7: 1 . 